\title{
Development of DNA-based species-specific real-time PCR markers for four berry fruits and their application in commercial berry fruit foods
}

\author{
Jun An', Jun-Cheol Moon², Ju Hee Kim', Geum Sol Kim and Cheol Seong Jang ${ }^{1 *}$
}

\begin{abstract}
Berry fruits have attracted attention because of their purported benefits for aging, cardiovascular disease, and cancer. Therefore, highly priced berry fruits might be targets for food adulteration and fraud. In this study, eight speciesspecific primer sets based on the single nucleotide polymorphism of the chloroplast genomes of four berry fruits (aronia, blackberry, cranberry, and strawberry) were developed for quantitative real-time PCR (qPCR) analysis by SYBR Green staining with the aim of preventing berry fruit food fraud. The developed primer pairs exhibited high efficiencies ranging from 88 to $110 \%$ with strong correlation coefficients $\left(R^{2}>0.99\right)$ for the amplification of each target species. However, no clear correlation coefficients were evident for non-target species. To evaluate the practicality of the developed primers, 18 commercial berry fruit products were verified by qPCR analysis. The developed primer pairs were amplified to a low $C_{t}$ value (range 16.1-23.3) for the target species and proved capable of detecting target species in berry fruit commercial foods. Therefore, the developed qPCR-based species-specific markers could be suitable for the prevention of berry fruit food fraud and to verify marker reliability.
\end{abstract}

Keywords: Berry, Food fraud prevention, Real-time PCR, Species-specific DNA markers, SYBR Green

\section{Introduction}

Berry fruits have been implicated in the lessening or prevention of diseases, and account for a large percentage of the fruits consumed as part of the human diet [1]. Berry fruits are also widely used in processed and derived products, including dried and canned fruits, yogurt, drinks, jams and jellies, as well as fresh and frozen fruits [2]. It has been amply demonstrated that berry fruits contain antioxidant and anti-inflammatory polyphenols, such as anthocyanins and phenolic acids, which play an important role in aging [3] and the prevention and treatment of cardiovascular disease [4] and cancer [5]. Therefore, consumption of berry fruits has been rapidly increasing worldwide.

\footnotetext{
*Correspondence: csjang@kangwon.ac.kr

1 Plant Genomics Laboratory, Department of Bio-Resources Sciences, Kangwon National University, Chuncheon 24341, Republic of Korea Full list of author information is available at the end of the article
}

Food fraud, which exploits food buyers for economic benefit, has a long history. The United States Grocery Manufacturers Association estimates that food fraud costs the global food industry $\$ 10-\$ 15$ billion annually, affecting about $10 \%$ of all sold commercial foods [6]. In response, various technologies incorporating molecular markers and biochemical analysis as two examples have been developed for prevent food fraud involving plants, such as saffron [7], orange [8], Orostachys japonica [9], and Cynanchum wilfordii [10]. However, prevention of food fraud for berry fruits is relatively unexplored. In general, chemical analysis is time-consuming and has limitations related to repeatability and reproducibility [11]. As an alternative to chemical assays, DNA-based assays are considered excellent tools for the identification of plant species in commercial foods. However, research on the classification of berry fruit based on DNA is also scant. DNA-based methods for detecting contamination with berry fruits in commercial foods are needed. 
Chloroplast genes are generally present in hundreds of copies per cell, and chloroplast genomes are protected from decomposition during food processing since they are enclosed by two membrane layers [12]. Thus, chloroplast genomes have been widely used in plant species identification to develop species-specific detection methods [13] as well as in evolutionary studies. In particular, the chloroplasts maturase K (matK) and RubisCO large-subunit genes $(r b c L)$ have proven to be excellent for DNA barcoding-based species identification $[14,15]$. The use of DNA barcoding for plant species identification has been studied [16, 17]. In addition, the $\operatorname{trn} L-\operatorname{trn} F$ region is frequently used along with $m a t K$ and $r b c L$ for DNA barcoding-based species identifications due to the extensive polymorphisms among species $[18,19]$.

DNA-based polymerase chain reaction (PCR) analyses have been widely used for preventing food fraud because of its economic and timesaving advantages compared to biochemical analyses. In particular, the high accuracy and sensitivity of quantitative real-time PCR (qPCR) assays could enable the detection of very low levels of target DNA in commercial foods. In this study, we developed four berry fruit species-specific molecular markers using DNA polymorphisms of chloroplast genes with the aim of utilizing the markers to prevent food fraud, and verified their application in commercial berry fruit food products.

\section{Materials and methods}

\section{Sample preparation}

Four species of berry fruits were used (Table 1): aronia (Aronia melanocarpa), blackberry (Rubus fruticosus), cranberry (Vaccinium macrocarpon), and strawberry (Fragaria $\times$ ananassa). All were purchased from Korea plant nursery (http://www.treeinfo.com, Taean, Korea). A total of 18 commercial berry fruit products were purchased from local or oversea markets (Table 1).

\section{Genomic DNA extraction}

Genomic DNAs of all fruit leaves and commercial products were extracted using the i-genomic Plant DNA Extraction Mini Kit (iNtRON Biotechnology, Seongnam, Korea) according to the manufacturer's protocol. Extracted genomic DNA concentration was measured using a Qubit ${ }^{\circledR}$ 2.0 Fluorometer (Invitrogen, Life Technologies, Grand Island, NY, USA) with a Qubit dsDNA BR Assay Kit (Invitrogen). The amplification capacity of the extracted DNA was assessed with universal plant primer pairs that target a conserved 18S rRNA nuclear region [20].

\section{Sequence alignment and primer design}

Three chloroplast gene regions (matK, $r b c L$, and $t r n L$ $F)$ were used to develop species-specific molecular markers. All berry fruit chloroplast sequences were downloaded from the National Center for Biotechnology Information (NCBI, https://www.ncbi.nlm.nih. gov/). Downloaded chloroplast sequences were aligned

Table 1 Commercial berry products used in this study

\begin{tabular}{|c|c|c|c|}
\hline Numbers & Samples & Ingredient & Origin \\
\hline 1 & Aronia powder & Aronia $100 \%$ & Finland \\
\hline 2 & Aronia powder & Aronia $100 \%$ & Korea \\
\hline 3 & Aronia powder & Aronia 100\% & Poland \\
\hline 4 & Aronia powder & Aronia $100 \%$ & Korea \\
\hline 5 & Aronia tea & Aronia, Apple, Hibiscus (not indicated) & Korea \\
\hline 6 & Blackberry powder & Blackberry $100 \%$ & Chile \\
\hline 7 & Blackberry powder & Blackberry $100 \%$ & Chile \\
\hline 8 & Blackberry powder & Blackberry $100 \%$ & Chile \\
\hline 9 & Blackberry powder & Blackberry $100 \%$ & Chile \\
\hline 10 & Blackberry tea & Blackberry 5\%, Jasmine 40\%, Oolong 49\% & India \\
\hline 11 & Cranberry powder & Cranberry 100\% & Finland \\
\hline 12 & Cranberry powder & Cranberry $100 \%$ & USA \\
\hline 13 & Cranberry powder & Cranberry 100\% & Canada \\
\hline 14 & Strawberry powder & Strawberry $100 \%$ & Korea \\
\hline 15 & Strawberry powder & Strawberry $100 \%$ & Korea \\
\hline 16 & Strawberry powder & Strawberry $100 \%$ & Korea \\
\hline 17 & Strawberry powder & Strawberry $100 \%$ & Korea \\
\hline 18 & Strawberry cookie & Rice $75 \%$, Strawberry 9\% & Korea \\
\hline
\end{tabular}


using ClustalW2 (ftp://ebi.ac.uk/pub/software/clust alw2/) and Software Bio-edit 7.2 (Ibis Biosciences, Carlsbad, CA, USA). The species-specific primer pairs were designed using Beacon Designer ${ }^{\mathrm{TM}}$ (PRIMER Biosoft, Palo Alto, CA, USA). All designed primer sets were synthesized by a commercial service (Macrogen, Seoul, Korea). The primer sequences used in this study are listed in Table 2.

\section{Real-time PCR analysis}

qPCR was carried out in a final volume of $20 \mu \mathrm{L}$ using a CFX Connect ${ }^{\mathrm{TM}}$ Real-Time PCR Detection System (BioRad, Hercules, CA, USA) with SYBR Green dye. The reaction mixture consisted $10 \mu \mathrm{L}$ of $\mathrm{SYBR}^{\circledR}$ Green TOP real qPCR 2xPreMIX (Enzynomics ${ }^{\mathrm{TM}}$, Daejeon, Korea), $10 \mathrm{ng}$ of genomic DNA and $10 \mathrm{pmol}$ of each primer sets, with adjustment to a final volume of $20 \mu \mathrm{L}$ with PCR-grade water. The experiment conditions were as follows: $10 \mathrm{~min}$ at $95{ }^{\circ} \mathrm{C}$, followed by 45 cycles of $10 \mathrm{~s}$ at $95{ }^{\circ} \mathrm{C}$, annealing at the appropriate annealing temperature $\left(\mathrm{T}_{\mathrm{m}}\right)$ and time of each primer pair, and $30 \mathrm{~s}$ at $72{ }^{\circ} \mathrm{C}$. The PCR products were denatured at $95{ }^{\circ} \mathrm{C}$ for $10 \mathrm{~s}$ and then annealed at $65^{\circ} \mathrm{C}$ for $5 \mathrm{~s}$. This step was followed by a melt-curve analysis at temperatures ranging from 60 to $95{ }^{\circ} \mathrm{C}$. For sensitivity analysis, fruit leaf DNAs of each species were diluted tenfold into five series $(0.001-10 \mathrm{ng} / \mu \mathrm{L})$ and used for real-time PCR. In addition, extracted each commercial product DNAs was quantitated to $10 \mathrm{ng}$ and used for real-time PCR.

\section{Cloning of PCR amplicons}

To identity PCR products amplified from the correct target regions, they were cloned using commercial product RBC T\&A Cloning Vector (Real Biotech Corporation, Taipei, Taiwan) and a ligation mix (TaKaRa Bio, Shiga, Japan) according to the manufacturer's protocol. Conventional PCR was performed using TaKaRa Ex Taq ${ }^{\mathrm{TM}}$ DNA polymerase (TaKaRa Bio). PCR reaction was performed with an initial denaturation $5 \mathrm{~min}$ at $95^{\circ} \mathrm{C}$, followed by 35 cycles of $10 \mathrm{~s}$ at $95^{\circ} \mathrm{C}, 30 \mathrm{~s}$ at $\mathrm{T}_{\mathrm{m}}{ }^{\circ} \mathrm{C}$ (each primer), $1 \mathrm{~min}$ at $72{ }^{\circ} \mathrm{C}$, and finally $5 \mathrm{~min}$ at $72{ }^{\circ} \mathrm{C}$. Then, the amplicon was cloned into the T\&A Vector and plasmid DNA was purified using the Plasmid Mini-Prep Kit (Elpis Biotech, Daejeon, Korea). Nucleotide sequences were analyzed by a commercial service (Macrogen).

\section{Determination of amplification efficiency, correlation coefficient, and limit of detection (LOD)}

To evaluate the correlation between DNA concentration and cycle threshold $\left(C_{t}\right)$, standard curves were obtained using tenfold diluted DNA samples of the four berry fruits species at concentrations of 0.001-10 ng. The correlation coefficient $\left(R^{2}\right)$ was determined by using the linear regression method $\left(R^{2} \geq 0.98\right)[21]$. The amplification efficiency was calculated on the basis of the standard curve using the equations $\mathrm{E}=10^{-1}$ /slope, and efficiency $(\%)=\left(\mathrm{E}^{-1}\right) \times 100$. The LOD was regarded as the analytical concentration at which the method detected the presence of a target gene in at least $95 \%$ of true-positive biological samples ( $<5 \%$ of false-negative results) [22].

Table 2 Information of developed primers used in this study

\begin{tabular}{|c|c|c|c|c|c|c|}
\hline Target species & Target gene & Primer & Length (bp) & Sequence $\left(5^{\prime} \rightarrow 3^{\prime}\right)$ & Size (bp) & $\mathrm{T}_{\mathrm{m}}\left({ }^{\circ} \mathrm{C}\right)$ \\
\hline \multirow[t]{2}{*}{ Plant system (positive control) } & $18 \mathrm{~S}$ rRNA region & $18 S$ rRNA_F & 25 & TCTGCCCTATCAACTTTCGATGGTA & 137 & 58 \\
\hline & & 18SrRNA_R & 25 & AATTTGCGCGCCTGCTGCCTTCCTT & & \\
\hline \multirow[t]{4}{*}{ Aronia (Aronia melanocarpa) } & matk & matK_F & 19 & CTTTACATTTATTACGACG & 110 & 54 \\
\hline & & matK_R & 19 & TAGGAGCAAGAATAATCG & & \\
\hline & $\operatorname{trn} L-F$ & $\operatorname{trn} L-F \_F$ & 21 & TATCGTTTTGTTAGCGATTCA & 224 & 59 \\
\hline & & $\operatorname{trn} L-F_{-} R$ & 22 & CAAAGTTTCAGTACAGTACAAG & & \\
\hline \multirow[t]{4}{*}{ Blackberry (Rubus fruticosus) } & $\operatorname{trn} L-F$ & $\operatorname{trn} L-F_{-} F$ & 20 & ACTCTACTCTTTCACAAACC & 124 & 57 \\
\hline & & $\operatorname{trn} L-F \_R$ & 20 & CACATTATTCAAAGATGCTG & & \\
\hline & $r b c L$ & $r b c L_{-} F$ & 18 & GTTGGAGAGACCGTTTCG & 171 & 60 \\
\hline & & $r b c L_{-} R$ & 23 & GTAATCGTGCATTATGATAGGAG & & \\
\hline \multirow[t]{4}{*}{ Cranberry (Vaccinium macrocarpon) } & matk & matK_F & 20 & GGTTTTCAAAGACCCTTTCC & 120 & 60 \\
\hline & & matK_R & 21 & CATTCCCAGAAATTGACAAGG & & \\
\hline & $r b c L$ & $r b c L_{-} F$ & 20 & ATCATATTCACTCGGGTACT & 94 & 59 \\
\hline & & $r b c L \_R$ & 23 & TCAATATAATCATCACGCAGTAA & & \\
\hline \multirow[t]{4}{*}{ Strawberry (Fragaria × ananassa) } & matk & matK_F & 18 & AACCAGGAAGAATCCATC & 173 & 54 \\
\hline & & matK_R & 19 & CATTGGAATAATTGGAAAC & & \\
\hline & $\operatorname{trn} L-F$ & $\operatorname{trn} L-F_{-} F$ & 18 & ATAAGCAAGCCTTGTGTG & 179 & 60 \\
\hline & & $\operatorname{trn} L-F \_R$ & 17 & TTATCCAGGCCCTGGTC & & \\
\hline
\end{tabular}




\section{Results and discussion}

\section{Species-specific qPCR primers design}

Three chloroplast gene sequences (matK, trnL-F, and $r b c L$ ) of the four berry fruits were obtained from NCBI. The chloroplast sequences were aligned using ClustalW2 to identify single nucleotide polymorphisms (SNPs) or InDels (insertions and deletions) among the four berry fruits. A host of SNPs and/or InDels were found in each of three genes among the sequences (Additional file 1: Fig. S1), suggesting that the differences could be useful for designing the species-specific primers.

Species-specific primers were designed using a commercial program based on SNPs or InDels of the berry fruit cpDNA sequences. Since DNA of foods tends to be degraded into short fragments during food processing steps, such as heat treatment, small PCR products are better amplified compared to large PCR products in processed foods [23]. Therefore, we designed eight species-specific primer pairs that could amplify short amplicons of 94-224 bp to detect target species in processed foods (Table 2). All species-specific primers were designed based on two or more SNPs to clearly distinguish each berry fruit (Additional file 1: Fig. S1).

\section{Evaluation of the amplification efficiency and sensitivity of the species-specific primers}

We evaluated the efficiency and sensitivity of the developed primers for qPCR analyses using tenfold serially diluted DNA (10-0.001 ng) of each fruit and examining individual statistical measurements using a regression analysis. The quality of extracted DNAs of each fruits was first evaluated by qPCR using universal plant primer pairs [20]. The 18S rRNA was efficiently amplified in all samples, with $C_{t}$ values in the range of 14.12-14.35. Then, efficiencies of all species-specific primers were confirmed to be in the range of $88-108 \%$ with a strong correlation coefficient $\left(R^{2}>0.99\right)$ for the target species (Table 3$)$. In addition, the slopes of the linear equations for the target species ranged from -3.13 to -3.63 . However, the correlation coefficient of non-target (other) species was not evident in all the developed primer pairs (Fig. 1). These results suggest that the developed primer pairs could be very suitable for detecting the target species. To

Table 3 Slope, correlation coefficient, efficiency, and $C_{t}$ values obtained by qPCR assay using the developed primers

\begin{tabular}{|c|c|c|c|c|c|c|}
\hline Target species & 18S rRNA & Primer & Y (Slope) & $\begin{array}{l}\mathrm{R}^{2} \text { (correlation } \\
\text { coefficients) }\end{array}$ & Efficiency (\%) & $C_{t}^{a}$ \\
\hline \multirow[t]{2}{*}{ Aronia (Aronia melanocarpa) } & $14.33 \pm 0.02$ & matK & -3.589 & 0.993 & 90.1 & 29.4 \\
\hline & & $\operatorname{trn} L-F$ & -3.359 & 0.996 & 98.5 & 28 \\
\hline \multirow[t]{2}{*}{ Blackberry (Rubus fruticosus) } & $14.12 \pm 0.03$ & $r b c L$ & -3.422 & 0.998 & 96 & 25.7 \\
\hline & & $\operatorname{trn} L-F$ & -3.529 & 0.998 & 92 & 26.3 \\
\hline \multirow[t]{2}{*}{ Cranberry (Vaccinium macrocarpon) } & $14.29 \pm 0.05$ & matK & -3.527 & 0.998 & 92.1 & 25.3 \\
\hline & & $r b c L$ & -3.131 & 0.996 & 108.6 & 27.6 \\
\hline \multirow[t]{2}{*}{ Strawberry (Fragaria $\times$ ananassa) } & $14.35 \pm 0.01$ & matk & -3.63 & 0.993 & 88.6 & 28.1 \\
\hline & & $\operatorname{trn} L-F$ & -3.347 & 0.997 & 98.9 & 26.5 \\
\hline
\end{tabular}

${ }^{\text {a }} C_{t}$ values represent the limit of detection of $10 \mathrm{pg}$ of DNA from each species using the species-specific primers

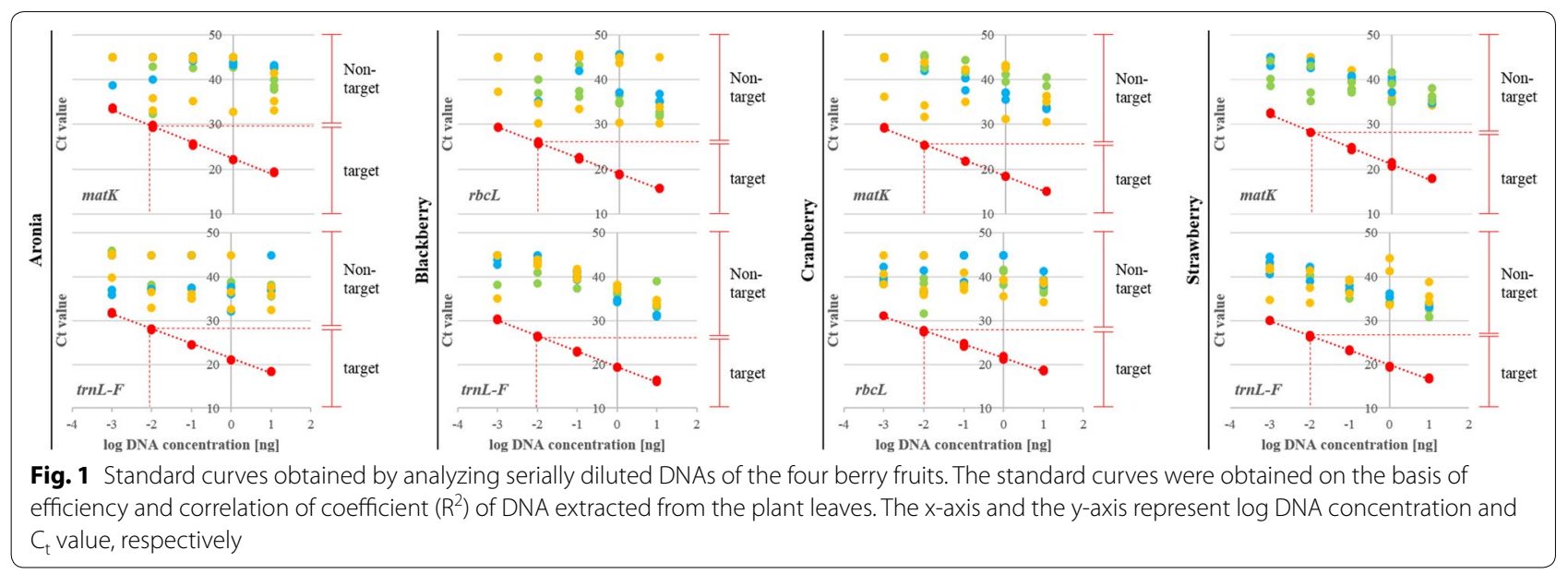


confirm whether the PCR amplicons were derived from the correct target regions, the products were cloned and sequenced. No differences were found between both sequences NCBI deposited and amplified by the primer (Additional file 1: Fig. S2). Subsequently, target-specificities of the developed primers were evaluated using endpoint PCR (30 cycles) and the amplicons were visualized by agarose gel electrophoresis (Fig. 2a). All PCR products were amplified with each of the desired size in the genomic DNA. In addition, sharp peaks were obvious for the target species in PCR products amplified with each of the developed primer pairs (Fig. 2b). These findings suggest that the develop primer pairs could be useful for distinguishing between the four berry fruit species.

\section{Application of the primers to commercial food products of berry fruits}

To gauge the applicability of the developed primer pairs, 18 commercial products were purchased from local or oversea markets and then tested. Prior to applying the commercial foods, the universal primers were used to test whether the DNA extracted from the food products were suitable for the qRT-PCR assay. Results of the qPCR analysis with the universal plant primer pairs (18S rRNA amplification) showed low $\mathrm{C}_{\mathrm{t}}$ values in the range of 12.83-17.15 for all products, indicating that the quality of the extracted DNA was suitable for further assays.

Based on qPCR results, $C_{t}$ values of the 18 commercial products were determined (Table 4 ). All $C_{t}$ values amplified with target primers were lower than the LOD
(10 pg $C_{t}$ values). However, $C_{t}$ values with non-target primers were higher than the LOD. Our results for all 18 commercial products were consistent with the indicated ingredients, suggesting that the developed primer pairs would be useful to detect the target berry species in commercial foods.

Fruits are commonly processed to fruit juices. The market sectors for fruit juices have been rapidly growing. Therefore, highly priced fruit juices have been targets for food adulteration and fraud [24]. Since the most frequent profit-procedures are simple dilution with water, the addition of sugar or cheap alternatives, a host of nontargeted high-performance liquid chromatography-mass spectrometry metabolomics fingerprinting techniques coupled with chemometric analysis have been developed for the juice-type food authenticity testing [24]. Since the impact of berry fruits intake on human health, performance, and disease as superfoods have been firmly established, they have been commonly consumed worldwide in fresh and processed forms, such as dried powders and teas [5]. Therefore, alternative detection technologies would be useful for detection of berry fruit adulteration and fraud.

SYBR Green-based qPCR analysis is a useful tool for the detection and quantification of species-specific nucleotides. This method is faster and more stable than other chemical assays [25]. SYBR Green-based techniques can detect other plant species in processed foods, such as hazelnuts [26], almonds [27], DNA allergens [28], and C. wilfordii and C. auriculatum [10]. In this study,
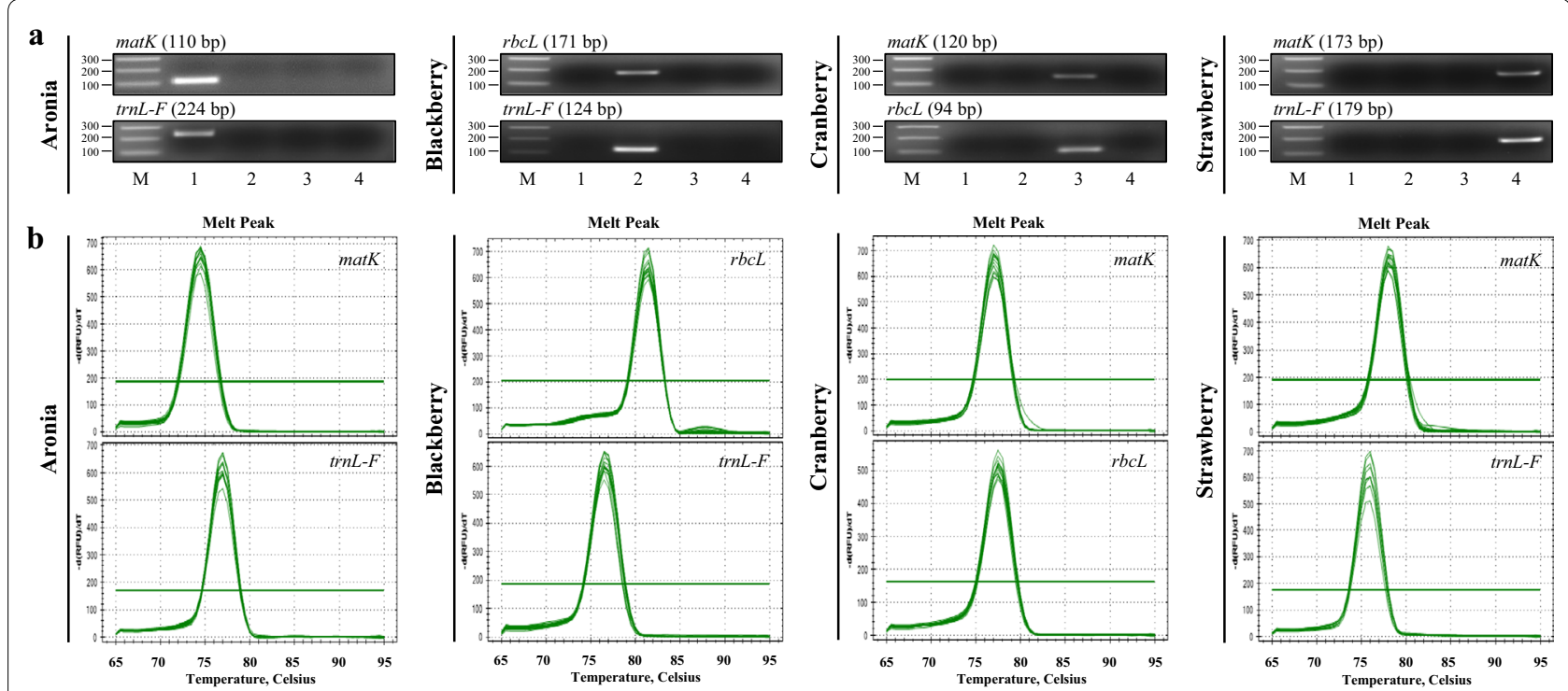

Fig. 2 a PCR products (30 cycles) of each species-specific primer sets were electrophoresed to confirm cross-reactivity, $\mathbf{b}$ melt peak analysis to confirm amplification of a single PCR amplicon. M, 1 kb Plus DNA ladder marker; Lane 1, aronia; Lane 2, blackberry; Lane 3, cranberry; Lane 4, strawberry 
Table 4 The amplified $C_{t}$ values of 18 commercial berry food products by qPCR using the developed primer sets

\begin{tabular}{|c|c|c|c|c|c|c|c|c|c|}
\hline \multirow{2}{*}{$\begin{array}{l}\text { Sample } \\
\text { numbers }\end{array}$} & \multirow[t]{2}{*}{ 18S rRNA } & \multicolumn{2}{|l|}{ Aronia } & \multicolumn{2}{|l|}{ Blackberry } & \multicolumn{2}{|l|}{ Cranberry } & \multicolumn{2}{|l|}{ Strawberry } \\
\hline & & (matK) & $(t r n L-F)$ & $(t r n L-F)$ & $(r b c L)$ & (matK) & $(r b c L)$ & (matK) & $(t r n L-F)$ \\
\hline 1 & $14.56 \pm 0.06$ & $18.42 \pm 0.18$ & $19.39 \pm 0.17$ & $37.14 \pm 1.46$ & $35.62 \pm 0.49$ & $31.52 \pm 1.12$ & $31.97 \pm 0.13$ & $35.84 \pm 0.43$ & $36.05 \pm 0.34$ \\
\hline 2 & $14.54 \pm 0.07$ & $18.63 \pm 0.07$ & $19.07 \pm 0.01$ & $38.79 \pm 0.66$ & $36.12 \pm 0.67$ & $40.78 \pm 1.92$ & $38.02 \pm 0.63$ & $37.67 \pm 0.95$ & $35.45 \pm 0.92$ \\
\hline 3 & $12.83 \pm 0.13$ & $18.69 \pm 0.3$ & $19.72 \pm 0.13$ & $39.77 \pm 0.83$ & $35.17 \pm 0.48$ & $40.5 \pm 2.87$ & $39.18 \pm 1.16$ & $35.17 \pm 0.41$ & $35.96 \pm 0.68$ \\
\hline 4 & $13.66 \pm 0.06$ & $19.29 \pm 0.14$ & $19.78 \pm 0.17$ & $33.16 \pm 0.35$ & $32.14 \pm 0.21$ & $32.88 \pm 3.13$ & $30.71 \pm 0.18$ & $34.43 \pm 0.19$ & $34.57 \pm 0.41$ \\
\hline 5 & $15.49 \pm 0.07$ & $22.77 \pm 0.28$ & $22.37 \pm 0.18$ & $35.36 \pm 1.25$ & $35.82 \pm 0.29$ & ND & $36.8 \pm 1.18$ & $34.73 \pm 0.12$ & $39.85 \pm 0.9$ \\
\hline 6 & $13.92 \pm 0.11$ & $34.93 \pm 0.25$ & ND & $17.97 \pm 0.16$ & $17.82 \pm 0.08$ & $35.45 \pm 2.3$ & $35.5 \pm 0.51$ & $33.29 \pm 0.18$ & $35.29 \pm 0.59$ \\
\hline 7 & $13.96 \pm 0.16$ & $40.12 \pm 2.73$ & ND & $16.33 \pm 0.19$ & $16.18 \pm 0.16$ & $38.94 \pm 5.62$ & $38.14 \pm 1.72$ & $33.2 \pm 0.61$ & $33.84 \pm 0.22$ \\
\hline 8 & $14.08 \pm 0.15$ & $40.18 \pm 3.36$ & ND & $16.5 \pm 0.05$ & $16.28 \pm 0.07$ & $34.89 \pm 2.4$ & $34.46 \pm 0.5$ & $34.48 \pm 0.23$ & $35.37 \pm 0.36$ \\
\hline 9 & $14.07 \pm 0.1$ & $40.75 \pm 2.56$ & ND & $16.59 \pm 0.18$ & $16.1 \pm 0.1$ & $40.58 \pm 3.65$ & $39 \pm 1.39$ & $32.71 \pm 0.08$ & $34.35 \pm 0.26$ \\
\hline 10 & $15.55 \pm 0.07$ & $34.8 \pm 0.42$ & $38.18 \pm 0.99$ & $22.38 \pm 0.12$ & $24.3 \pm 0.08$ & $40.06 \pm 0.94$ & $38.37 \pm 0.46$ & $36.67 \pm 4.07$ & $34 \pm 1.68$ \\
\hline 11 & $15.62 \pm 0.16$ & ND & $39.48 \pm 2.96$ & $37.37 \pm 0.35$ & $40.23 \pm 6.33$ & $19.23 \pm 0.01$ & $22.22 \pm 0.13$ & $42.76 \pm 0.85$ & $38.29 \pm 0.7$ \\
\hline 12 & $15.92 \pm 0.18$ & ND & $40.84 \pm 0.43$ & $31.35 \pm 0.18$ & $32.38 \pm 0.35$ & $19.37 \pm 0.08$ & $23.35 \pm 0.24$ & $41.47 \pm 0.38$ & $33.87 \pm 0.51$ \\
\hline 13 & $15.68 \pm 0.15$ & ND & $35.99 \pm 1.28$ & $31.42 \pm 0.15$ & $33.96 \pm 0.43$ & $18.17 \pm 0.01$ & $20.3 \pm 0.11$ & $40.33 \pm 0.22$ & $33.4 \pm 0.2$ \\
\hline 14 & $14.32 \pm 0.05$ & $39.75 \pm 1.96$ & $N D$ & $34.63 \pm 0.34$ & $30.45 \pm 0.17$ & $38.37 \pm 3.48$ & $40.42 \pm 0.11$ & $17.04 \pm 0.18$ & $18.2 \pm 0.04$ \\
\hline 15 & $17.15 \pm 0.13$ & $37.39 \pm 2.75$ & ND & $35.62 \pm 0.76$ & $38.59 \pm 2.75$ & $36.73 \pm 1.36$ & $38.75 \pm 1.53$ & $20.37 \pm 0.07$ & $21.03 \pm 0.08$ \\
\hline 16 & $13.6 \pm 0.06$ & $36.85 \pm 0.4$ & $40.89 \pm 1.65$ & $36.3 \pm 0.03$ & $35.23 \pm 1.33$ & $37.72 \pm 0.34$ & $41.32 \pm 3.38$ & $17.55 \pm 0.03$ & $18.81 \pm 0.13$ \\
\hline 17 & $13.59 \pm 0.14$ & $35.54 \pm 0.63$ & $38.11 \pm 1.54$ & $39.35 \pm 0.63$ & $40.1 \pm 0.64$ & $37.49 \pm 2.06$ & $42.9 \pm 1.88$ & $16.22 \pm 0.07$ & $18.02 \pm 0.12$ \\
\hline 18 & $15.92 \pm 0.05$ & $34.04 \pm 0.65$ & $37.92 \pm 1.18$ & $30.17 \pm 2.98$ & $34.13 \pm 0.6$ & $38.4 \pm 0.96$ & $37.4 \pm 0.46$ & $22.97 \pm 0.21$ & $21.01 \pm 0.15$ \\
\hline
\end{tabular}

qRT-PCRs were performed with three technical replicates

Numbers in italic indicate $C_{t}$ values of species-specific primers in each sample

we report the development of a DNA-based SYBR Green qPCR assay for rapid and sensitive species-specific detection (up to $10 \mathrm{pg}$ DNA) of four berry fruits. In additional, the markers were applied successfully to 18 commercial berry fruit foods. The developed molecular markers could be useful for detection of food fraud and adulteration in commercial berry fruits foods markets.

\section{Additional file}

Additional file 1: Figure S1. Alignments of three chloroplast gene sequences of Aronia melanocarpa (Aronia), Rubus fruticosus (Blackberry), Vaccinium macrocarpon (Cranberry), and Fragaria $\times$ ananassa (Strawberry) using ClustalW2 program. Designed species-specific primers are represented by arrows and include Red for aronia; black for blackberry; green for cranberry; and blue for strawberry. (A) matK gene, (B) rbcL gene, and $(C) \operatorname{trnL}-F$ gene. Figure $\mathbf{S}$. Comparison of nucleotide sequences between $P$ the NCBI database and PCR amplicons produced by speciesspecific primers. (A) Aronica matK primer; (B) Blackberry trnL-F primer; (C) Cranberry matK primer; and (D) Strawberry trnL-F primer.

\section{Authors' contributions}

CSJ conceived of the overall study. JA, J-CM, and CSJ co-wrote the paper. JA, GSK, and JHK performed the experiments and analyzed the data. All authors read and approved the final manuscript.

\section{Author details}

1 Plant Genomics Laboratory, Department of Bio-Resources Sciences, Kangwon National University, Chuncheon 24341, Republic of Korea.
${ }^{2}$ Agriculture and Life Sciences Research Institute, Kangwon National University, Chuncheon 24341, Republic of Korea.

\section{Acknowledgements}

This research was supported by a Grant (17162MFDS065) from Ministry of Food and Drug Safety in 2018.

\section{Competing interests}

The authors declare that they have no competing interests.

\section{Publisher's Note}

Springer Nature remains neutral with regard to jurisdictional claims in published maps and institutional affiliations.

Received: 30 October 2018 Accepted: 21 January 2019

Published online: 03 March 2019

\section{References}

1. Bazzano LA (2005) Dietary intake of fruit and vegetables and risk of diabetes mellitus and cardiovascular diseases. WHO, Geneva

2. Seeram NP (2006) Berries. Nutritional oncology, 2nd edn. Elsevier, Amsterdam, pp 615-628

3. Thangthaeng N, Poulose SM, Miller MG, Shukitt-hale B (2016) Preserving brain function in aging: the anti-glycative potential of berry fruit. NeuroMol Med 18(3):465-473

4. Vendrame S, Del Bo C, Ciappellano S, Riso P, Klimis-zacas D (2016) Berry fruit consumption and metabolic syndrome. Antioxidants 5(4):34

5. Seeram NP (2008) Berry fruits for cancer prevention: current status and future prospects. J Agric Food Chem 56(3):630-635 
6. Johnson R (2014) Food Fraud and "Economically Motivated Adulteration" of Food and Food Ingredients, Congressional Research Service, Washington, D.C.

7. Villa C, Costa J, Oliveira MBP, Mafra I (2017) Novel quantitative real-time PCR approach to determine safflower (Carthamus tinctorius) adulteration in saffron (Crocus sativus). Food Chem 229:680-687

8. Han J, Wu Y, Huang W, Wang B, Sun C, Ge Y, Chen Y (2012) PCR and DHPLC methods used to detect juice ingredient from 7 fruits. Food Control 25(2):696-703

9. An J, Moon J, Jang CS (2018) Markers for distinguishing Orostachys species by SYBR Green-based real-time PCR and verification of their application in commercial O. Japonica food products. Appl Biol Chem 61(5):499-508

10. Kim JH, Moon J, Kang TS, Kwon K, Jang CS (2017) Development of cpDNA markers for discrimination between Cynanchum wilfordii and Cynanchum auriculatum and their application in commercial C. wilfordii food products. Appl Biol Chem 60(1):79-86

11. Yalcinkaya B, Yumbul E, Mozioglu E, Akgoz M (2017) Comparison of DNA extraction methods for meat analysis. Food Chem 221:1253-1257

12. Garino C, De Paolis A, Coisson JD, Bianchi DM, Decastelli L, Arlorio M (2016) Sensitive and specific detection of pine nut (Pinus spp.) by realtime PCR in complex food products. Food Chem 194:980-985

13. Provan J, Powell W, Hollingsworth PM (2001) Chloroplast microsatellites: new tools for studies in plant ecology and evolution. Trends Ecol Evol 16(3):142-147

14. CBOL Plant WORKING GROUP (2009) A DNA barcode for land plants. Proc Natl Acad Sci USA 106(31):12794-12797

15. Li F, Kuo L, Rothfels CJ, Ebihara A, Chiou W, Windham MD, Pryer KM (2011) $\mathrm{rbcL}$ and matK earn two thumbs up as the core DNA barcode for ferns. PLOS ONE 6(10):e26597

16. Asahina H, Shinozaki J, Masuda K, Morimitsu Y, Satake M (2010) Identification of medicinal Dendrobium species by phylogenetic analyses using matK and $r b c L$ sequences. J Nat Med 64(2):133-138

17. Burgess KS, Fazekas AJ, Kesanakurti PR, Graham SW, Husband BC, Newmaster SG, Percy DM, Hajibabaei M, Barrett SC (2011) Discriminating plant species in a local temperate flora using the $r b c L$ matK DNA barcode. Methods Ecol Evol 2(4):333-340
18. Cabelin VL, Alejandro GJ (2016) Efficiency of matK, rbcL, trnH-psbA, and trnL-F (cpDNA) to molecularly authenticate philippine ethnomedicinal apocynaceae through DNA barcoding. Pharmacogn Mag 12(Suppl 3):S384-S388

19. De Groot GA, During HJ, Maas JW, Schneider H, Vogel JC, Erkens RH (2011) Use of rbcL and trnL-F as a two-locus DNA barcode for identification of NW-European ferns: an ecological perspective. PLOS ONE 6(1):e16371

20. Allmann M, Candrian U, Hffelein C, Lthy J (1993) Polymerase chain reaction (PCR): a possible alternative to immunochemical methods assuring safety and quality of food. Detection of wheat contamination in nonwheat food products. Z Lebensm Unters Forsch 196:248-251

21. Ramakers C, Ruijter JM, Deprez RHL, Moorman AF (2003) Assumption-free analysis of quantitative real-time polymerase chain reaction (PCR) data. Neurosci Lett 339(1):62-66

22. Ferreira T, Farah A, Oliveira TC, Lima IS, Vitório F, Oliveira EM (2016) Using real-time $P C R$ as a tool for monitoring the authenticity of commercial coffees. Food Chem 199:433-438

23. Lo Y, Shaw P (2018) DNA-based techniques for authentication of processed food and food supplements. Food Chem 240:767-774

24. Hong E, Lee SY, Jeong JY, Park JM, Kim BH, Kwon K, Chun HS (2017) Modern analytical methods for the detection of food fraud and adulteration by food category. J Sci Food Agric 97(12):3877-3896

25. Ponchel F, Toomes C, Bransfield K, Leong FT, Douglas SH, Field SL, Bell SM, Combaret V, Puisieux A, Mighell AJ (2003) Real-time PCR based on SYBRgreen I fluorescence: an alternative to the TaqMan assay for a relative quantification of gene rearrangements, gene amplifications and micro gene deletions. BMC Biotechnol 3(1):18

26. Arlorio M, Cereti E, Coisson J, Travaglia F, Martelli A (2007) Detection of hazelnut (Corylus spp.) in processed foods using real-time PCR. Food Control 18(2):140-148

27. Pafundo S, Gulli M, Marmiroli N (2009) SYBR ${ }^{\circledR}$ GreenER $^{\mathrm{TM}}$ real-time PCR to detect almond in traces in processed food. Food Chem 116(3):811-815

28. Pafundo S, Gullì M, Marmiroli N (2010) Multiplex real-time PCR using $\mathrm{SYBR}^{\circledR}$ GreenER $^{\mathrm{TM}}$ for the detection of DNA allergens in food. Anal Bioanal Chem 396(5):1831-1839

\section{Submit your manuscript to a SpringerOpen ${ }^{\circ}$ journal and benefit from:}

- Convenient online submission

- Rigorous peer review

- Open access: articles freely available online

- High visibility within the field

- Retaining the copyright to your article

Submit your next manuscript at $\boldsymbol{\nabla}$ springeropen.com 